Estudios Románicos, Volumen 29, 2020, pp. 297-318

ISSN: 0210-4911

eISSN: 1989-614X

DOI: https://doi.org/10.6018/ER.425681

\title{
LA FIGURA DE PEDRO DE GRACIA DEI: UN BOSQUEJO BIOGRÁFICO
}

(The figure of Pedro de Gracia Dei: a biographical steck)*

\author{
Natalia Anaís Mangas Navarro** \\ Universitat d'Alacant
}

\begin{abstract}
The biography of Pedro de Gracia Dei is characterized by presenting numerous questions, due to limited data that we know about the author. We are in the face of a shape who, although he was linked to the environment of the Catholic Monarchs, the great chronicles that were made about this reign by writers also tied to the court do not reveal information about him. Having to do without, therefore, the historical sources that we can consider more reliable to be able to draw an approximate profile of Gracia Dei, we must go to other documents, as well as establish conjectures from the few news that the author himself captured in his production literary. The rubrics of his works that were copied during the $16^{\text {th }}, 17^{\text {th }}$ and even $18^{\text {th }}$ centuries will also be of great interest in this regard, although they are characterized by having generated even more controversy about the possible positions that Gracia Dei would play at throughout his life.
\end{abstract}

Keywords: Pedro de Gracia Dei; biography; Catholic Monarchs; Gran Capitán; arms officer.

Resumen: La biografía de Pedro de Gracia Dei se caracteriza por presentar numerosos interrogantes, debido a los escasos datos que conocemos sobre el autor. Nos encontramos ante una figura que, aunque estuvo vinculada al entorno de los Reyes Católicos, las magnas crónicas que se realizaron sobre este reinado por parte de escritores ligados también a la corte no nos revelan información sobre él. Teniendo que prescindir, por tanto, de las fuentes históricas que podemos considerar más fiables para poder trazar un perfil aproximado de Gracia Dei, debemos acudir a otros documentos, así como

${ }^{*}$ Este trabajo se enmarca en el proyecto Cancionero, romancero y fuentes impresas, del Ministerio de Economía, Industria y Competitividad (FFI2017-86313-P), financiado por la Agencia Estatal de Investigación (AEI) y el Fondo Europeo de Desarrollo Regional (FEDER/UE), cuyo investigador principal es Josep Lluís Martos.

** Dirección para correspondencia: Natalia Anaís Mangas Navarro. Tomelloso, Ciudad Real (nataliamangas_4@hotmail.com). 
establecer conjeturas a partir de las pocas noticias que el propio autor plasmó en su producción literaria. Resultarán también, de gran interés al respecto, las rúbricas de sus obras que se copiaron durante los siglos XVI, XVII e, incluso, XVIII, si bien se caracterizan por haber generado más controversia aún sobre los posibles cargos que desempeñaría Gracia Dei a lo largo de su vida.

Palabras clave: Pedro de Gracia Dei; biografía; Reyes Católicos; Gran Capitán; oficial de armas.

Las incógnitas que giran en torno a la figura de nuestro autor comienzan por el propio nombre del poeta, que Pascual de Gayangos ya cuestionó en la introducción al Blasón general y Nobleza del Universo, de Gracia Dei, donde explica que:

Gracia Dei no pudo ser nombre, sino más bien especie de renombre usado por los heraldos, farautes ó reyes de armas de la época, á la manera que los del emperador Carlos V de Alemania, y I de España, se apellidaban Castilla, Aragón, Borgoña, Flandes, Tosón de Oro y así á este tenor, los de Francisco I, Bretagne, Guienne etc., y los de Henrique VIII de Inglaterra, Clarrencieux, Richemont, Windsor etc (1882: VIII) ${ }^{1}$.

Por tanto, Gayangos relaciona el nombre "Gracia Dei" con cargos oficiales de la época, pero sin ofrecer mucha más información al respecto. Si eso fuese así, sin embargo, sería extraño que otros personajes que hubiesen ocupado el mismo cargo no adoptaran este mismo sobrenombre, pero no encontramos a ningún otro "Gracia Dei" documentado a finales del siglo XV y principios del XVI, ni tampoco en años posteriores. A pesar de todo, la hipótesis de Gayangos ha arraigado en la bibliografía posterior, como es el caso de Couceiro (1951: 208-209), Tudela y Bueso en el prólogo a las Batallas y quinquagenas (Gonzalo Fernández de Oviedo 1983: XXXIII) ${ }^{2}$ y Gregorio de Andrés (1993: 234), que se limitan a aceptarla sin cuestionarla, ni fundamentarla.

Este panorama, caracterizado por la confusión y por meros indicios, empieza a esclarecerse -aunque no del todo-, cuando Infantes sugiere que tras el renombre "Gracia Dei" existe una intención de ocultar un apellido de posible origen converso ${ }^{3}$, aunque "no

1 Respecto a los sobrenombres que podían adoptar aquellos que desempeñaban dichos cargos incide también Martín de Riquer, que indica que "los oficiales de armas no eran conocidos por sus nombres personales de nacimiento o linaje, sino por los títulos que sus señores les imponían al «bautizarlos», títulos que transferían a sus sucesores" (1986: 41).

2 «Porque ya se ve, para comienzo de equívocos, que se trata de un sobrenombre a disposición de quien quiera apropiárselo» (Fernández de Oviedo 1983: XXXIII).

3 No es extraño que Infantes proponga esta posibilidad, si atendemos, por ejemplo, al escritor Johannes Baptista, que adopta el mismo sobrenombre que nuestro autor, "Gratia Dei” y que fue un médico hebreo declarado abiertamente como judío converso (Fernández de Córdova Miralles 2005: 697-699). Escribió De Confutatione hebraicae sectae (1500), obra de la que se imprimieron dos ediciones, una el 14 de mayo de 1500 en Roma, en el taller de Eucharius Silber y otra el 20 de septiembre en Estrasburgo, en la imprenta de Martin Flach, según consta en el Catálogo bibliográfico de la colección de incunables de la Biblioteca Nacional (Martín Abad 2010: 381). Actualmente, se conservan ambos impresos en los fondos de la misma, con signatura I/2654 e I/2538, respectivamente. 
alcanzamos a delimitar su sentido exacto y que puede ir desde una iluminación espiritual espontánea hasta un meditado y culto cambio intelectual" (1995: 44). Tanto en un supuesto como en otro, podrían tratarse de hipótesis razonables, y más aún si atendemos a la delicada situación en el plano religioso que se vivía en aquellos momentos. Nuestro autor pudo adoptar este apellido con la finalidad de reafirmar públicamente su apuesta por la fe católica, debido a las persecuciones hacia falsos cristianos que se dieron en los últimos años del siglo xv en Castilla ${ }^{4}$ y que desembocaron, finalmente, con la expulsión de los judíos en 1492.

En esta línea, se ha llegado a plantear la hipótesis de que el nombre completo del autor fuese un pseudónimo, pues Ceballos-Escalera y Gila (1993: 70) identifica a Pedro de Gracia Dei con Antonio de Villamayor, rey de armas. Dicha identificación se ha dado por buena y, así, se ha incorporado a la Bibliografía Española de Textos Antiguos (BETA), aunque con interrogante 5 . Sin embargo, de la misma manera que ocurre con Pedro de Gracia Dei, el nombre de Antonio de Villamayor no lo encontramos como rey de armas en los documentos oficiales de la época, ni figura nadie que haya desempeñado una función similar con ese nombre. Perea Rodríguez, ante esta situación, se plantea que, quizá, se trate de una confusión con Antonio de Sotomayor, rey de armas de Felipe II, que en el siglo XVI copió algunas obras de Gracia Dei y en ocasiones se le atribuye la autoría de las mismas (2007: 1371, n. 124). La única certeza que tenemos, por tanto, es que este poeta firma sus obras como «Gracia Dei» y así lo citan las rúbricas en todos sus testimonios.

Se baraja un arco temporal para su posible fecha de nacimiento, que oscila entre 1465 y 1470, aunque todas ellas basadas en conjeturas a partir de otros documentos que sí están fechados y que no pueden más que orientarnos. Gayangos, en el prólogo al Blasón general, (1882: vI) establece que pudo ser hacia 1469, datación que asume Jardin (2016: § 6), mientras que Infantes propone, aunque con interrogante, el año $1465^{6}$. Si atendemos a su producción literaria, concretamente a los dos incunables que se imprimieron en vida del autor, podríamos obtener algunos datos al respecto. La Criança y virtuosa dotrina se imprime en Salamanca ca. $1488^{7}$ y el Blasón General y Nobleza del Universo en Coria en 1489. Una obra y otra presuponen, por sus características, una sólida formación y madurez intelectual, así como unos conocimientos acerca de determinadas materias que solo pueden explicarse en base a una trayectoria de estudio e innumerables lecturas especializadas. Así las cosas, si aceptamos la fecha propuesta

$4 \quad$ Es durante el reinado de los Reyes Católicos cuando se implanta la Inquisición Real en Castilla para combatir las prácticas de los judeoconversos, con la bula del papa Sixto IV en 1478 de Exigit sincerae devotionis (Antonio Rubio 2009: 185). En contraste con esta drástica medida, es sabido que los Reyes Católicos mantenían buena relación con los judeoconversos, ya que contaron con la presencia y ayuda de muchos de ellos en su corte, como es el caso de Diego de Valera, Hernando del Pulgar o Fernando Álvarez de Toledo (Hernández Gassó 2007: 688), lo que no excluiría, por tanto, que, en caso de pertenecer a este grupo religioso, Pedro de Gracia Dei desempeñara también alguna función en el entorno regio.

5 Por ello, Faulhaber reclama un estudio completo de Pedro de Gracia Dei «para establecer que es la misma persona que el rey de armas Antonio de Villamayor» (BETA bioid 1282).

6 Así consta en el Diccionario Biográfico Español de la Real Academia de la Historia. La entrada referente a Pedro de Gracia Dei puede consultarse a través del siguiente enlace: <http://dbe.rah.es/biografias/73484/ pedro-de-gracia-dei>.

7 Para un estudio material del incunable, remito a Mangas Navarro (2020b: 181-204). 
por Gayangos, resultaría cuanto menos sorprendente que Gracia Dei compusiera la Criança hacia 1488, pues contaría con la edad de 19 años. Resulta más lógico aceptar la opción que ofrece Infantes, lo que no significa, en cualquier caso, que pudiese haber sido incluso antes.

Sabemos por los incunables de la Criança y virtuosa dotrina y del Blasón General y Nobleza del Universo dos datos que nos ofrece el mismo autor, presentes en los paratextos de ambas obras, como son su origen gallego y su vinculación a la Universidad de Salamanca:

La criança y virtuosa dotrina dedicada a la illustre y muy / esclarecida señora doña isabel primera infante de castilla en / la universidad de salamanca: por un gallego hijo del dicho studio: renombre gracia dei (h. $\left.1^{\text {r }}\right)$.

Blason general de todas las insignias del universo dedi / cado Al serenissimo príncipe alto y muy poderoso rey de / portogal: Hecho en la uniuersidad de Salamanca por un / gallego hijo del dicho estudio renonbre Gracia dey (h. 25r).

Algunos datos más sobre su origen gallego están recogidos en el Rosal de Nobleza de Antonio de Barahona, genealogista coetáneo a Gracia Dei, que presume en su obra, en más de una ocasión, de ser sobrino de nuestro autor: "Antonio de Baraona natural de Triana extramuros y epalensis sobrino de Gracia Dey hijo de su hermana, interprete de las Españas natural nazido en una caseria extramuros de la ciudad de Betanzos" (BNE, ms. 6175, f. $91^{\text {r }}$. No obstante, la figura de Barahona también se caracteriza por presentar lagunas importantes, pese a los intentos que se han llevado a cabo por aclarar su vida y obra (Parejo Delgado 1998: 129-183) ${ }^{8}$. El autor no ofrece en ninguna otra parte del Rosal el nombre de su madre, la que sería hermana de Gracia Dei, cuestión que hubiese resultado de gran ayuda y que, por tanto, limita las pesquisas biográficas de ambos personajes.

No es extraño que un gallego estudiase en la Universidad de Salamanca, porque, más allá del prestigio que pudiera tener en la época, la realidad es que la Universidad de Santiago de Compostela no se fundó, como tal, hasta el año $1495^{9}$, casi una década después de la impresión de la Criança y virtuosa dotrina. La Universidad de Salamanca era el referente para este tipo de estudios superiores en la meseta Norte y en el noroeste peninsular, como indican los datos analizados por Rodríguez-San Pedro (2002: 17), mientras que constituían una minoría aquellos estudiantes procedentes de Extremadura y Andalucía.

Durante el reinado de los Reyes Católicos, la ciudad salmantina se convierte, además, en el principal referente cultural e intelectual de la península ibérica gracias a la Universidad, que constituye, a su vez, el vehículo de difusión de los ideales monárqui-

8 Es posible que Antonio de Barahona compartiese y tomase prestados materiales textuales de su tío para la composición de sus obras. Véase al respecto Ladero Quesada 1995: 222, n. 1.

9 Se creó el Estudio de Gramática en 1495 por Lope Gómez de Marzoa y se consolidó en el año 1504 con la bula del papa Julio II, por petición de Diego de Muros, uno de los hombres de confianza de la Casa Real y vinculado con otras universidades del territorio, como la de Salamanca o Valladolid (Cabeza de León y Fernández Villamil 1945: 32). 
$\cos ^{10}$. Isabel y Fernando llevaron a cabo un plan de reforma en los órganos de gobierno, con la finalidad de conformar un estado totalmente centralizado y con un importante intervencionismo regio. Para este proceso, fue determinante dotar a dichos órganos de «aquellos mecanismos, soporte legal y personal especializado necesarios para que los monarcas puedan ejercer su autoridad en las instituciones que los representan» (Hernández Gassó 2009: 119).

Pero este intervencionismo por parte de los Reyes Católicos, así como la estrecha relación con la Universidad de Salamanca, no siempre fue así, lo que contrasta con la mayoría de los reinados anteriores. Desde su creación, a finales de 1218 y por orden de Alfonso IX de León ${ }^{11}$, esta institución estuvo influenciada por las autoridades pontificias, al constituirse su Estudio General como una prolongación de la escuela catedralicia, en la que la Catedral se convertía en espacio clave en el desarrollo de la vida universitaria ${ }^{12}$. Con el tiempo, las influencias papales y pontificias quedan relegadas a un segundo plano, imperando, en primera instancia, el intervencionismo regio a través del Consejo de Castilla:

El fin es el servicio y satisfacción de las necesidades del reino entendido en su sentido más amplio. De ahí que los reyes encargados de velar por esos intereses supremos tengan derecho estricto a intervenir, moldear la vida académica en conformidad con las exigencias de la nación (Beltrán de Heredia 1970: 37).

Una de las reformas más notables que llevaron a cabo los Reyes Católicos fue reducir la participación estudiantil en la universidad, que la venía caracterizando desde su fundación, en favor de una acusada aristocratización del poder, que recaía en «los catedráticos de propiedad y en las oligarquías colegiales» (Rodríguez-San Pedro 2002: 21).

Precisamente porque la Universidad de Salamanca fue clave en la formación del proyecto regio de los Reyes Católicos, advirtieron de la necesidad de impulsar otros centros de cierta historia, como lo eran los Estudios Generales de Valladolid ${ }^{13}$ o de

10 Gómez Moreno alude a una suerte de «Salamanca connection», debido al prestigio indiscutible que adquiere la ciudad durante el reinado de los Reyes Católicos (2008: 61).

11 Para ello, tomó como inspiración el modelo de corporación estudiantil de la universidad de Bolonia, enmarcándose así dentro de las llamadas «universidades meridionales de orientación jurídica» (Rodríguez-San Pedro 2002: 11). Atendiendo al panorama general europeo, la universidad salmantina se fundó con posterioridad en comparación a otras universidades importantes: la de Bolonia fue fundada alrededor de 1088; la de Oxford en torno a 1096 y la de París en torno a 1150.

12 Podemos conocer de primera mano dichas relaciones gracias al importante trabajo realizado por Marcos Rodríguez (1964), que atiende exclusivamente a los libros de claustros de la Universidad de Salamanca. Además, se detiene en la figura del maestrescuela, pieza clave en el entorno universitario medieval y fundamental para entender la vinculación entre ambas corporaciones (1964: 24-26).

13 La Universidad de Valladolid se fundó hacia 1250, pero fue durante el reinado de los Reyes Católicos cuando recibió realmente ayuda económica, así como también destaca la fundamental labor realizada por Alonso de Burgos, obispo de Palencia, que comenzó la construcción del Colegio de San Gregorio (Gómez Moreno 2008: 62-63). Para un estudio detallado sobre la Universidad de Valladolid remito a la obra de Alcocer Martínez (19181931). 
Lérida $^{14}$, así como la propia creación de las universidades de Sigüenza ${ }^{15}$ y Sevilla ${ }^{16}$. Mención aparte merece la Universidad de Alcalá de Henares, que adoptó varias nomenclaturas en la época, como Universidad Complutense o Universidad Cisneriana, al ser fruto de la labor del Cardenal Cisneros en 1498 y al que los Reyes Católicos le encomendaron desarrollar su proyecto político e ideológico. Por su parte, Cisneros, apoyándose en su pensamiento reformista, empleó todos sus esfuerzos en fortalecer la formación del clero castellano ${ }^{17}$.

Pero el aspecto más importante que explica la total vinculación entre universidad y monarquía es que de dicha institución salen los letrados y funcionarios que los Reyes incorporan a su entorno para llevar a cabo su proyecto político. Hernández Gassó habla de una «relación bidireccional», en tanto en cuanto los monarcas intervienen en la universidad para adaptarla a sus necesidades, a la vez que las autoridades académicas intentan acercarse al entorno regio a través de los graduados en la universidad (2009: 130).

Ante este panorama, pudiéramos pensar que Pedro de Gracia Dei incorporó la referencia a Salamanca como una vía de promoción, con la única finalidad de acceder al entorno regio y servirle de utilidad a los monarcas ${ }^{18}$. Aunque Infantes (1995: 44) se inclina a pensar que el vínculo entre Gracia Dei y la Universidad sería más afectivo que otra cosa, puesto que no hay rastro de él ni en los Cartularios ni Bularios de la misma, ${ }^{19}$ parece lícito suponer que nuestro autor sí estuvo ligado de forma física a esta institución, ya que se denomina «hijo del dicho studio». Aun así, esta hipótesis carece de base documental, ya que los Libros de matrículas que se conservan en el Archivo Histórico de la Universidad de Salamanca están fechados muy posteriormente al período en que nuestro autor pudiera haber cursado allí sus estudios (1546-1845) ${ }^{20}$.

En las Cuentas de Gonzalo de Baeza (1955: 588) encontramos una alusión a Gracia Dei como «bachiller», lo que parece confirmar que, efectivamente, pudo haber alcanzado dicho título en la Universidad de Salamanca. Concretamente en esta Universidad, solo se podía optar al grado de bachiller si la persona estaba instruida in grammaticalibus (García y García 1989: 32). La colación de grados era una parte fundamental dentro del entramado universitario, otorgando a los estudiantes la garantía de una sólida

14 Respecto a las universidades en Cataluña, el primer Estudio General se constituyó en Lérida en el año 1300, pero durante el reinado de los Reyes Católicos destaca la Universidad de Barcelona, ya que fue el rey Fernando el que le otorga la confirmación del privilegio en el año 1487 y las ordenaciones de 1507 y 1508 (Gómez Moreno 2008: 65).

15 La Universidad de Sigüenza surge en 1476, estrechamente relacionada con la fundación del Colegio Grande de San Antonio de Portaceli, pero no fue hasta el año 1486 cuando el papa Sixto IV aprueba sus Constituciones. Remito al trabajo de Gil Peces (1998).

16 Es en el año 1502 cuando los Reyes Católicos conceden una cédula para la creación de la Universidad de Sevilla, pero hasta 1516 no se puso en marcha. Sin embargo, lo que realmente contribuyó a que la universidad sevillana tomara forma y se consolidase fue la unión con el Colegio Mayor Santa María de Jesús en el año 1551.

17 La Universidad de Alcalá de Henares fue la única que pudo competir con la salmantina en cuanto a prestigio y cantidad de estudiantes, hasta que, a mediados del siglo xvi, ocupó el primer puesto en la lista de centros universitarios hispanos.

18 Martínez Alcorlo señala que "en el caso de la Criança es patente que se inserta en un período de búsqueda de mecenazgo regio por parte del autor" (2016: 230).

19 Aun así, Infantes advierte que hace falta una revisión completa de los archivos, si bien es lógico pensar que Gracia Dei no aparezca en dichos documentos de carácter pontificio y regio.

20 Estos documentos están digitalizados y pueden consultarse a través del siguiente enlace: $<$ http://ausa. usal.es/ausa matriculas.php>. 
formación, así como la facilidad para acceder a puestos de trabajo de la administración civil o eclesiástica. En la Universidad de Salamanca se expedían, además del grado de bachiller, otros dos más: el de licenciado y doctor.

Además de su origen gallego y su vinculación a la Universidad de Salamanca, la Criança y virtuosa dotrina y el Blasón general y Nobleza del Universo nos permitirían bosquejar el propósito de Pedro de Gracia Dei al componer e imprimir ambas obras. El primero de los incunables, impreso en Salamanca $c a$. 1488, está dedicado a la infanta Isabel, primogénita de los Reyes Católicos, como indica su rúbrica inicial: «dedicada a la illustre y muy esclarecida señora doña Isabel, primera infante de Castilla» $\left(\mathrm{h} . \mathrm{1}^{\mathrm{r}}\right)$. A pesar de ello y de lo inequívoco de la rúbrica, algunos investigadores como Gallardo (1888: 102), Paz y Meliá (1892: 381), Infantes (1995: 48) o Carrasco Manchado (2002: 412 , n. 28) han identificado a la destinataria como la mismísima reina Católica.

Sin embargo, ya desde el prólogo inicial, queda claro que es una obra dedicada a la primogénita de los Reyes Católicos y no a su madre. El texto en sí, ya desde su inicio, es, incluso, más explícito, al referir a la infanta en relación a sus padres: «A vos, la hija del invicto rey / y de la única grande reyna» $\left(\mathrm{h} .1^{v}\right)$. Es lógico, por tanto, que algo tan obvio como la identificación de la destinataria de este tratado sí que haya sido advertido por otros investigadores, aunque solo en las últimas décadas y conviviendo con bibliografía que mantenía esta falsa noticia (Gonzalo Fernández de Oviedo 1983: XxxIII-XXXIV; Dutton 1990: 478; Sanz Hermida 2004: 379-394; Perea Rodríguez 2007: 1372, n.129; Gómez Redondo 2012: 485; Martínez Alcorlo 2015: 375-390).

Durante este reinado adquiere notable importancia la figura de los infantes, especialmente la del príncipe Juan y la infanta Isabel, que acaban desempeñando un papel de intermediarios en las relaciones de mecenazgo establecidas entre los artistas y los monarcas ${ }^{21}$. Por tanto, no es extraño que nuestro autor tuviera como propósito ganarse la simpatía de los Reyes Católicos recurriendo a la figura de la infanta Isabel, ofreciéndole a ella directamente la obra: «por ende suplico resciba señora / esta obrezilla por gracia dei» (h. $1^{v}$ ). En este mismo sentido, Pedro de Gracia Dei no duda en dirigirse, incluso ya en el cuerpo del texto, al rey Fernando, manifestando su intención de encomendarse a su servicio y poniendo de relieve un dato que, muy probablemente, tuvo mucho que ver para su posterior vinculación con la corte de los Reyes Católicos:
Ya vuestra merced sabe, señor, cómo mi padre de tal logar Ticio, ha seído muerto en su servicio como vasallo y buen servidor. Yo, con aqueste zelo y amor pensé: «do el padre quiso morir, es muy grande el hijo servir, por de mercedes ser merecedor» (h. $\left.5^{\vee}\right)$.

$21 \quad$ En el caso concreto de Isabel, «su papel vehicular imponía como centro de interés y patronazgo el de su madre, otorgándole un rol de intermediaria como vía de acceso al poder regio y al amparo de la corona» (Martínez Alcorlo 2016: 199). 
$\mathrm{Si}$, realmente, el padre de Gracia Dei estuvo al servicio de los Reyes Católicos, es probable que, precisamente por ello, nuestro autor quisiera seguir sus pasos y que esta pudiese ser una razón más sobre la que los monarcas pudieran depositar la confianza en él.

En este sentido, el texto da noticia de un suceso que puede ayudar a reconstruir la biografía de Pedro de Gracia Dei, ya que deja entrever lo que parece ser un destierro sufrido durante el reinado de Juan II de Aragón, pues sigue dirigiéndose así al rey Fernando:
Sabrá, señor, vuestra señoría, que vuestro padre, que sancta gloria aya, estando, señor, en Soria, por maldizientes y melenconía, me mandó tomar quanto tenía; y agora, dizen, vuestra grandeza descarga sacando muchos de pobreza; suplico, señor, que vea la mía (h. $\left.5^{v}\right)$.

Si tenemos en cuenta que Juan II de Aragón murió en 1479, esta fecha supone un terminus ante quem para el suceso aquí referido. Aunque Gracia Dei adopta la primera persona, podemos suponer, por la edad que tendría entonces, que, en realidad, no solo se refiere a él, sensu stricto, sino a su familia: «me mandó tomar quanto tenía». Si ponemos en relación los datos que nuestro autor nos ofrece en esta copla con hechos históricos acaecidos a partir de la segunda mitad del siglo Xv en lugares concretos -y que pudieran tener consecuencias en la población, como castigos o destierros-, podemos plantear varias hipótesis.

El dato más confuso que nos encontramos es la referencia que hace Gracia Dei a la ciudad de Soria en el verso "estando, señor, en Soria", ya que el contexto en el que se inserta puede dar lugar a una doble interpretación: que la persona que estaba en Soria era Juan II de Aragón y desde allí dio la orden de destierro o expulsión o que, por el contrario, tanto Gracia Dei -y, por ende, a su familia-, como Juan II de Aragón se encontraban en Soria en el momento de lo sucedido. Si atendemos al discurso del texto, la segunda opción es la que parece más probable, lo que implicaría que Juan II de Aragón, estando Gracia Dei en Soria con su familia, le «mandó tomar quanto tenía». En este punto debemos tener en cuenta que la ciudad de Soria pertenecía a la Corona de Castilla ${ }^{22}$, por lo que la potestad que pudiera tener Juan II de Aragón sobre esas tierras sería muy limitada, si no nula ${ }^{23}$.

22 Desde 1134, la ciudad de Soria ya formaba parte definitivamente de la Corona de Castilla. En torno a 1369, Enrique II de Trastámara, como recompensa por las útiles ayudas y servicios prestados en la guerra contra su hermano Pedro I, entregó en señorío al mercenario francés Bertrand du Guesclin las ciudades de Soria, Almazán, Deza, Atienza, Serón y Monteagudo de las Vicarías. Cuando Bertrand du Guesclin obtuvo en dinero el valor del señorío de estas villas —un total de 100.000 francos de oro_- volvió a Francia y la ciudad de Soria pasó de nuevo al realengo. A mediados del siglo xv, Soria fue entregada a la reina Isabel de Portugal, segunda esposa del rey Juan II de Castilla y madre de Isabel la Católica, que la mantuvo en señorío hasta su muerte en 1496 (Asenjo González 1999: 535).

23 Desde 1474 la que tenía potestad sobre el reino de Castilla era Isabel la Católica. Con la firma de la Concordia de Segovia el 15 de enero de 1475 se establecieron las funciones que recaían tanto en la figura de la reina como en el rey don Fernando (Vicens Vives 2006: 400-402). También cabe la posibilidad de que este suceso que da a conocer Gracia Dei ocurriera antes de la llegada al trono de Isabel la Católica, por lo que el poder del reino de Castilla estaba en manos de Enrique IV; en cualquier caso, tampoco Juan II de Aragón ejercería autoridad alguna sobre el mismo. 
Asenjo González, tras analizar documentos y archivos históricos de diferentes ciudades, agrupa en tres delitos diferentes aquellos que suponían la pena del destierro o exclusión a finales del siglo xv y principios del xvi: delitos políticos, violencia delincuencial y mala conducta. Entre 1460 y 1520, concretamente en Soria, y junto a Guadalajara y Santander, no se registra ningún destierro (2012-2014: 79-81). Los delitos políticos, se caracterizaban porque "la pena se conecta con el uso que se hacía en la corte regia para corregir abusos, deslealtades y traiciones, todos ellos delitos de laesa maiestatis (lesa majestad) contra el rey o contra el reino" (2012-2014: 82).

Quizá no podamos hablar de un destierro propiamente dicho y este pasaje del texto reflejaría, en última instancia, una desvinculación entre la familia de Gracia Dei y Juan II de Aragón, motivada, probablemente, por algún tipo de deslealtad por parte del padre de nuestro autor, que estaría a su servicio. De ser así, podría explicarse que, una vez perdida la confianza del monarca, buscara protección -y finalmente la consiguiera- en la corte castellana que desde 1470 formaba parte su hijo Fernando, ya que uno de los versos afirma que el padre de Gracia Dei «ha seido muerto en su servicio».

Gallardo, por su parte, señalaba que algunas coplas de la obra sugerían cierta persecución hacia el padre del autor (1888: 103), aunque no identifica de cuáles se trata. A lo largo del texto, solo encontramos alusión al padre de Gracia Dei en esta copla, por lo que Gallardo debería referirse, sin lugar a dudas, a la ya citada. Tal persecución pudiera relacionarse con aspectos de carácter religioso, si damos por válida la idea que propuso Infantes sobre el origen converso de nuestro autor, a partir del apellido o sobrenombre (1995: 44). Respecto al adjetivo "maldizientes", quizá Gracia Dei lo utiliza para referirse a aquellos que provocaron dicho "destierro" o "exclusión", pues pudiera estar relacionado con las luchas y acusaciones que llevaban a cabo los cristianos viejos contra todos aquellos conversos que seguían manteniendo las prácticas judaizantes en su entorno más íntimo ${ }^{24}$.

Lo cierto es que hasta 1477 no hay constancia de altercados ni revueltas en Soria relacionados con este grupo religioso, cuando se proclama una ley mediante la cual los judíos debían vivir apartados de la ciudad para que no convivieran con la población cristiana. Esta decisión sí que trajo consigo algunas tensiones en la población soriana, ya que no hubo consenso sobre el lugar en el que debían quedar apartados los judíos (Asenjo González 1999: 596). Estos problemas se agravaron con las diferentes posturas que querían adoptar respecto a esta situación el concejo de Soria, por un lado, y el alcalde de la ciudad, Jorge Beteta, por otro, que ofreció protección a los judíos.

Aunque es cierto que no podemos asegurar la verdadera razón que motivó a Juan II de Aragón a romper los lazos con Gracia Dei y su familia, tales hipótesis nos permiten hacernos una idea de las circunstancias en que se pudo haber producido. En cualquier caso, conviene valorar estos datos, dado que la Criança y virtuosa dotrina es la única

24 Véase Rábade Obradó 1999: 369-93. Debemos entender maldizientes, por tanto, como aquellos que 'echan maldiciones sobre algo', sino como los que 'hablan con mordacidad en perjuicio de alguien' (DEL, s.v. maldecir). Véase, en este sentido, unos versos de Juan del Encina que recoge el CORDE a propósito de ese adjetivo: «Los maldizientes mundanos / sufren menguas, más que menguas / que se esfuerçan en las lenguas / acovardando las manos» (CORDE, s.v. maldiziente). 
obra de Pedro de Gracia Dei que nos ofrece información personal de estas características.

En 1489, poco después de la aparición del incunable de la Criança y virtuosa dotrina, sale del taller extremeño de Bartolomé de Lila, en Coria, el Blasón de todas las insignias del universo ${ }^{25}$, donde se vuelve a dejar constancia de la vinculación de Gracia Dei con la Universidad de Salamanca, más allá del lugar de impresión de esta obra:

Este blason general de las insignias del bniverso dedicado / al serenissimo prinçipe alto y muy poderosso rey de po / togal: fue impresso y en tallado en la çibdad de coria po / maestro bartolome de lila flamenco año de mill cccc lxxxix (h. 72v).

Dedicado expresamente al rey João II de Portugal, este tratado nobiliario parece haber sido concebido como «un regimiento heráldico pensado para el infante don Alfonso de Portugal, en el arco de fechas en que se iba a casar con la princesa Isabel» (Gómez Redondo 2012: 485), y cuya finalidad primera sería consolidar la relación entre ambas cortes tras la guerra peninsular ${ }^{26}$. Efectivamente, en 1490, solo un año después de la impresión del Blasón, la infanta Isabel contrajo matrimonio con Alfonso de Portugal, el príncipe heredero. Los dos textos, Criança y Blasón, parecen complementarse, erigiéndose como dos obras donde Gracia Dei «afianza las relaciones políticas y literarias entre ambas cortes peninsulares, la castellana y la portuguesa» (Martínez Alcorlo 2016: 229).

Para Martínez Alcorlo, el Blasón sería la prueba de las relaciones de mecenazgo entre Pedro de Gracia Dei y el rey portugués João II (2016: 216), pero no disponemos de bases documentales que lo confirmen. De lo que sí tenemos certeza es de la estrecha relación de nuestro autor con la corte de los Reyes Católicos, aunque actualmente se barajan varias opciones y no está del todo claro el cargo que pudo desempeñar dentro del círculo regio. Basándonos en evidencias estrictamente contemporáneas a la vida del autor, solo contamos con tres testimonios que otorgan una función específica a Gracia Dei en la corte de los monarcas. Dos de ellos, localizados en el archivo del Real Patrimonio catalano-aragonés, reflejan esta relación. En el primero, datado el 23 de abril de 1497, Fernando el Católico le entrega a Gracia Dei algunas vestimentas para que acuda a la boda del príncipe Juan:

Fragment de l'estat de comptes dels diners despesos en robes dels oficials de la cort reial per a vestir-se en les festes del casament del príncep. Relació de les que s'han donat a Gràcia Dei, cronista.

De la librea que s'à donat a sens oficials de la cancelleria de sa magestat y scrivans de la tessoreria y scrivania de ració e moços de capella de sa magestat (Ruiz i Calonja 1953-1954: 249).

25 Más conocido como Blasón general y Nobleza del Universo por la edición facsímil con prólogo de Gayangos de 1882 .

26 Tras la guerra castellana contra Portugal (1475-1479), a la vez que se firmaba el acuerdo de paz entre ambos reinos, el 2 de junio de 1479 se concertó el matrimonio de la Infanta Isabel con Alfonso de Portugal. Para una rigurosa y clara visión sobre este acontecimiento y el posterior matrimonio en el año 1490 remito a los trabajos de Suárez Fernández (1992 y 1998). 
En el segundo, con fecha del 26 de febrero de 1500, se hace explícita la donación de cinco mil maravedíes para la compra de un caballo, también por parte del rey Fernando:

El rei mana donar graciosament a Gràcia Dei, cronista de casa seva, cinc mil maravedisos per a cornprar-se un cavall. De Gràcia Dei, de $N^{M}$. maravedís per a un cavall. Al magnífich etc., de part etc. Mana sa magestat que doneu y pageu a Gràcia Dei, coronista de la casa de sa magestat, quinque mille morabatinos monete Castelle, los quals sa magestat li mana donor y pagar graciosament per a comprar-se un cavall. Scrit en la ciutat de Granada a ·XxvI dies del mes de febrer anno a nativitate Domini millesimo quingentesimo (Ruiz i Calonja 1953-1954: 250).

La última fecha documentalmente probada en la que encontramos rastro de Pedro de Gracia Dei es en 1503, a través de las Cuentas de Gonzalo de Baeza, en las que se incluye un asiento al librar «al bachiller Gracia Dey, contino de su Alteza, un jubón e un bonete de terçiopelo negro e un tabardo e un sayo e unas calças de contray negro, de que su Alteza le hizo merçed para su vestuario» (1956: 588).

Como podemos comprobar, cada documento otorga a Gracia Dei un cargo distinto; en los dos primeros aparece como «cronista» de la Casa Real, oficio que describe Fernández de Oviedo (2006: 162) y que compara con el de los evangelistas, ya que debían desempeñarlo personas temerosas de Dios y tratar de cosas importantes, pero de forma llana, dejando a un lado el estilo elocuente y retórico. En 1480 los Reyes Católicos, prescindiendo de la figura de Alonso de Palencia, nombraron cronista real a Hernando del Pulgar. No sabemos con seguridad el año de su muerte, pero los historiadores la datan hacia 1493. Los documentos que designan a Gracia Dei como cronista están fechados en 1497 y 1500, de manera que pudiera ser factible que nuestro autor desempeñara dicho cargo a partir de $1493^{27}$. Lo cierto es que no conservamos ninguna obra que pruebe que Gracia Dei fuera cronista de la Casa Real, a excepción de la primera parte de una Crónica en defensa del rey Pedro I, y cuya autoría continúa suscitando muchas dudas a día de hoy ${ }^{28}$.

27 El origen del oficio del cronista se remonta a los comienzos de la Edad Media, pero no es hasta el reinado de Juan II de Castilla cuando se realiza el nombramiento de un cronista real, Juan de Mena. En un principio, se nombrará únicamente a un cronista; bajo el reinado de Enrique IV se nombraron a dos y con la llegada de los Reyes Católicos llegaron a figurar hasta tres cronistas (Hernández Martínez 2013: 240-241), como es el caso de Diego de Valera, Hernando del Pulgar, Juan de Flores o Joan Margarit, todos ellos pertenecientes a las últimas décadas del siglo Xv. Ya en el siglo XVI, en el año 1509, Fernando el Católico nombra cronista real a Antonio de Nebrija.

28 Se trata de la Relación del rey don Pedro y su descendencia, editada por Andrés (1994: 207-249). Los problemas de autoría derivan por los distintos escritores que figuran en los testimonios que transmiten esta crónica. Está dividida en dos partes claramente diferenciadas: en la primera de ellas se identifica a Gracia Dei como autor -aunque algunos manuscritos señalan una autoría conjunta en la que intervienen Gracia Dei y Juan de Castro-y consiste en una exculpación de los crímenes e injusticias que cometió el rey Pedro I. El texto termina con una anotación que incluyen la mayoría de los testimonios: «Hasta aquí llegó Gracia Dei». La segunda parte de la obra tiene como núcleo central el linaje de los Castilla hasta, aproximadamente 1580, y se atribuye indistintamente a Diego de Castilla, deán de Toledo, o a Alonso de Castilla. La obra se transmite en numerosos códices de la Biblioteca Nacional de España: mss. 628, 10640, 3555, 3896, 3083, 1354 y 2778, 1500, 1652, 8841, 5950,1115 y 13209. Véase al respecto los trabajos de González de Fauve et al. 2006: 111-144 y Perea Rodríguez 2017: 151-181. 
Sin embargo, si atendemos a las Cuentas de Gonzalo de Baeza aparece como «bachiller» y «contino» de la reina. Esta última institución, la de los continos, parece característica de la Castilla de los Reyes Católicos: se les denominaba así por su disponibilidad continua, basada en el acompañamiento regio. Tenían una quitación fija y las funciones que llevaban a cabo estaban vinculadas, principalmente, con aspectos político-administrativos, aunque algunos podían estar sujetos a disciplinas militares (Ladero Quesada 1998: 341-342). En este punto resulta importante destacar que en las Cuentas de Gonzalo de Baeza se registra un Pedro de Gracia, a quien se le otorgan $1.500 \mathrm{mrs}$ :

Por una nomina de la Reyna, fecha a 30-V del dicho año (1493), 439.500 mrs., quel dicho tesorero die e pago, por mandado de su Alteza, a los capellanes e cantores e moços de su capilla e del prinçipe e otras personas e oficiales de su casa, para sus ayudas de costas en Barçelona, en esta guisa: A Pedro de Gracia, 1.500 mrs (1955: 77).

Para Martínez Alcorlo, este Pedro de Gracia se refiere, sin ninguna duda, al autor de la Criança y virtuosa dotrina (2016: 211, n. 38). Lo cierto es que, en el índice onomástico de dichas Cuentas, los nombres «Gracia Dei» y «Pedro de Gracia» aparecen en entradas diferentes: el primero de ellos como bachiller y contino, y el segundo como oficial de la casa del príncipe. Si a esto sumamos que en el Archivo General de Simancas también se registra un Pedro de Gracia en calidad de ministril (González Arce 2016: 294), podemos presuponer que, efectivamente, nos encontramos ante dos personajes diferentes.

Pedro de Gracia sería, efectivamente, un oficial de la casa del príncipe Juan, en la que desempeñaría la función de ministril, es decir, de músico, papel que encaja con la nómina de la reina Isabel citada arriba, pues se refiere a «capellanes e cantores e moços de su capilla e del príncipe e otras personas e oficiales de su casa». No parece tener fundamento la idea de que Pedro de Gracia y Gracia Dei sean la misma persona, pues los cargos que se asignan a ambos personajes no tienen ningún tipo de relación, como así nos muestra González Arce (2016: 374 y 387) en la división que realiza para explicar los oficiales de la casa del príncipe Juan.

Asimismo, incidiría en el hecho de que nos encontramos ante personas diferentes que en la obra de nuestro autor no encontramos atisbos que prueben su cargo como ministril. De la misma manera que ocurría, por ejemplo, con la poesía de Juan del Encina, la de Gracia Dei debería haberse impregnado de algunos rasgos formales o de géneros poéticos que apuntaran a su relación con la música; sin embargo, la producción de nuestro autor se inscribe en campos más áridos, como la genealogía y la heráldica en su mayoría, lo que encaja mucho mejor con el perfil de cronista y rey de armas.

El cargo específico que desempeñaría Pedro de Gracia Dei en la corte de los Reyes Católicos es, de hecho, otro de los aspectos que ha generado numerosas controversias. Durante los siglos XVII y XVIII se produce una proliferación de copias manuscritas que 
recogen su obra', en las que las rúbricas lo designan como "Rey de armas", "Cronista" e incluso "Intérprete" de los Reyes Católicos. Según Infantes, debemos entender el último calificativo no como traductor, sino como nuncio o mensajero de los monarcas (1995: 44-45). Su cargo como rey de armas ha suscitado numerosas dudas, ya que no aparece designado como tal en ningún otro documento de la época, como sí lo hacen otros hombres que desempeñaron el mismo cargo. Según sabemos por Fernández de Oviedo, estos oficiales eran los encargados de acompañar al rey o al príncipe en las ceremonias y acontecimientos públicos, teniendo, además, la condición de embajadores:

un ofiçio onrado entre los militares, e en la Casa Real, e de muchas preeminencias [...] Estos reyes de armas van con sus cotas reales vestidas, delante del rey e del prínçipe, en los tiempos de las fiestas, e entradas de çibdades e villas, e en los abtos e cortes que requieren solemnidad. E pregonan e declaran en alta boz la voluntad real, quando declara a un cavallero por alevoso o traidor. Con un rey de armas embía el rey a desafiar a otro rey, o se declarar por su enemigo. Son seguros e tienen libertad por su ofiçio para ir y volver libremente con sus embajadas e mensajerías al real o hueste de los enemigos [...] Traen los tales ofiçiales de armas, demás de la cota real vestida, un escudo de oro encima del coraçón, con las armas e insignias reales de su título e nombre de tal rey de armas Fernández de Oviedo 2006: 152-153).

Son tres los rangos de estos oficiales: los propios reyes de armas, los heraldos of $f$ rautes, y los persevantes o poursuivants (Riquer 1986: 41). Para ser distinguidos, vestían con las armas reales, la cota real y un escudo de oro encima del corazón con los escudos de los distintos reinos (González Arce 2016: 56). Nicolás Antonio, en su Bibliotheca Hispana Nova, denominaba a Pedro de Gracia Dei como:

Catholicorum Regum haraldus, atque item chronographus, reliquit genealogicum opus metricum, quod diversimode solet apellari [...] Interpretem haraldumque idem munus intellige, nos dicimus Rey de Armas, Versibus, qui auctoris nostri sunt, nescio quis glossam adjunxit; cert glosographus Gratiam Dei in iisdem laudat (1788: 199).

El principal cometido de esta figura era la elaboración de tratados heráldicos, blasones y armoriales, en los que se reunían las armas de los linajes más importantes del reino. También organizaban torneos, acompañaban al rey a las batallas y estaban presentes en entierros o entradas reales. La acepción de heraldo u oficial de armas es, de hecho, la más aceptada entre los investigadores que se han acercado a bosquejar la figura de Gracia Dei (Ceballos-Escalera y Gila 1993: 92 y González de Fauve et al. 2006: 132), relegando el oficio de rey de armas a un segundo plano, debido a que ningún documento oficial de la época designa a nuestro autor con tal cargo.

29 Esto se debe a las funciones que desarrollaron los reyes de armas durante esos siglos, relegadas, únicamente, a la composición de armoriales y nobiliarios. La genealogía y la heráldica se convierten, por excelencia, en las materias fundamentales que explotan los reyes de armas, adquiriendo estas disciplinas una importancia sin precedentes. Sobre este aspecto remito a los trabajos de Guillén Berrendero (2013: 481-503 y 2015: 30-60). Para ello, los reyes de armas acuden a las obras escritas siglos atrás sobre estas materias. 
La última fecha documentada en la que encontramos rastro de Pedro de Gracia Dei es en el año 1503. Tras la muerte de la reina Isabel en 1504, varias son las hipótesis que se han planteado sobre el camino que debió tomar nuestro autor, como su paso al servicio de Carlos I (Infantes 1995: 45), o bien bajo el amparo de Juana de Castilla y Felipe de Habsburgo (Perea Rodríguez 2007: 1373), en una interpretación continuista de su servicio a los Reyes Católicos, y basándose en una copla que Gracia Dei le dedica a Juana I tras la muerte de su esposo Felipe en 1506 (ID1944). Tampoco descarta este investigador las andanzas de nuestro autor por distintas cortes peninsulares -pero no las ubica cronológicamente-, si atendemos a las dedicatorias de algunas de sus obras, que tienen como destinatarios al rey João II de Portugal o a Gonzalo Fernández de Córdoba, pero tampoco ofrece datos que corroboren tales conjeturas.

Hasta ahora, no disponíamos de documentación oficial ni de fuentes manuscritas que probaran las relaciones de mecenazgo que pudo tener Gracia Dei con otros nobles de la Península o reyes que no fueran los Católicos. Gracias a un códice de la Biblioteca Nacional de España, con signatura mss. $12.612^{30}$, quizá podamos reconstruir una parte de la vida de nuestro autor dentro de un arco de espacio y tiempo que hasta ahora se caracterizaba por la ausencia total de datos, esto es, entre $1503 \mathrm{y}$, como mínimo, hasta 1508 -incluso años posteriores. No obstante, debemos tomar esta información con cautela, ya que puede haber sufrido deturpaciones en el proceso de transmisión, que podrían moverse entre la alteración de la realidad hasta la adición de elementos ficcionales. Se trata de una copia manuscrita del siglo XvI que nos ofrece, a modo de glosas, un pasaje de la vida de Gracia Dei, a propósito del blasón que el autor le dedica a Gonzalo Fernández de Córdoba, el Gran Capitán ${ }^{31}$.

Benido el catolico rey don fernando de ytalia año de mil y quinientos y ocho trejo consigo aquel claro y escelente varon don gonçalo fernandes de cordova duque de sesa e terra nova marques de vitonto conde de santangelo señor dela baronia del señor de aragon gran condestable de napoles y por merecido renombre gran capitan deespaña.

Este claro varon rico de linaje bino en españa y fue en su tierra que es la ciudad de cordova y el rey passó a burgos y estando el rey cenando una noche pregunto a graçia dei si conoçia al gran capitan y el dijo que era mucho su señor el rey le dijo el

30 En el tejuelo, el título es Blasones de Gracia Dei. Sin embargo, el manuscrito también recoge composiciones del Licenciado Molina y Damián de Goes, en una suerte de compendio heráldico que no sigue un orden sistemático, sino que aglutina estrofas de estos tres autores.

31 Transcribo el texto tal cual se transmite en el manuscrito, caracterizado por escasos signos de puntuación. Solo desarrollo en cursiva las abreviaturas que, mediante signo, también se indican en el códice. Encontramos una copia de este pasaje en otro manuscrito, también del siglo XVI y con una estructura interna muy similar, en los fondos de la Real Biblioteca del Palacio de Madrid, con signatura II/660, cuyo título en el tejuelo es Linages y blasones. Además del pasaje de la vida de Gracia Dei, ambos manuscritos transmiten el Diálogo del Comendador griego Hernán Núñez de Toledo contra los médicos y boticarios. De nuestro autor, los dos testimonios recogen estrofas que forman parte del Blasón de las armas e insignias de los mejores y más principales linajes de Castilla (ID 1941), Blasones de ciudades y villas (ID $6967^{\text {bis }}$ ), Las mujeres reinas en España (ID 1943) y, en el caso del manuscrito II/660, también Las XV preguntas que hizo el Papa Julio a Gracia Dei sobre las excelencias de la reina doña Isabel. Para un estudio codicológico e interno sobre el testimonio de la Real Biblioteca, véase Mangas Navarro 2020a: 48-56. 
sabado biene aquí yo quiero ver que blason le areis y como os ba con el graçia dei le dijo esta copla al rey (f. 53').

El pasaje refleja, claramente, la relación de Gracia Dei con el rey Fernando, tal y como confirman documentos oficiales. Si bien no sabemos el grado de fiabilidad que podemos otorgar a este pasaje, podemos corroborar los datos referentes a la fecha y el lugar en que se enmarca este suceso: gracias al trabajo de Rumeu de Armas (1974: 343-349), donde se recoge el itinerario que realizaron los Reyes Católicos durante su reinado y, tras la muerte de la reina Isabel, los pasos que siguió el rey Fernando en solitario, sabemos que, en el año 1508, Fernando el Católico estuvo en Burgos desde enero hasta mediados de julio ${ }^{32}$. La llegada de Gonzalo Fernández Córdoba y del rey desde Italia a la que hace alusión este pasaje se relaciona con la guerra que se disputó para recobrar Nápoles ${ }^{33}$. Tras este episodio, se recrea un encuentro entre Gracia Dei y el Gran Capitán, que le ruega se ponga a su servicio, a lo que nuestro autor responde positivamente:

[...] e un dia yendo el gran capitan cabalgando vidolo que se desviava del e hiçole llamar e dijole por que lo haceis tan mal graçia dey rogueos que os fuesedes ami posada y q olgariamos y hablariamos y no abeis querido no lo agais asi. respondio gracia dey de echo me manda vuestra señoria que vaya alla si. quando quiere que enpieçe, el domingo que come conmigo el condestable de castilla, o que blason tengo echo a v.s. que placer ha de aver conmigo, pues por mi vida que sea asi, yo os prometo las manos llenas (f. $54^{v}$ ).

Tras este encuentro, llega el día en que ambos comen juntos y entra en juego otro personaje histórico, el condestable de Castilla, Pedro Fernández de Velasco que, tras leer Gracia Dei unos versos dirigidos al Gran Capitán, califica de noble a nuestro autor. Después, Gonzalo Fernández de Córdoba le entrega a Gracia Dei vestimentas y dinero:

32 Las relaciones entre Gonzalo Fernández de Córdoba y la corte castellana comienzan desde su juventud, cuando desempeñó el cargo de paje del infante Alfonso, hermano de Isabel la Católica. Cuando esta fue reconocida Princesa y heredera de Castilla y ya casada con Fernando, le hizo llamar para que se dispusiera a su servicio. El Gran Capitán pasó la mayor parte tiempo en la corte de los Reyes Católicos, exceptuando su intervención en la Guerra de Sucesión y en la guerra contra Granada y en la posterior guerra contra Italia (Valdecasas 1988: 7).

33 El 28 de noviembre de 1494 los Reyes Católicos nombran a Gonzalo Fernández Córdoba jefe del ejército que va a partir hacia Sicilia, para entrar en la Península Italiana y recuperar el reino de Nápoles, invadido por Carlos VIII de Francia. La primera campaña de Nápoles tiene lugar en los años 1495-1496; la segunda entre 1501 y 1503. El 2 de enero de 1504, gracias a la victoria del ejército que dirigía el Gran Capitán, finaliza la guerra con la rendición de la plaza fuerte de Gaeta, incorporándose de nuevo el reino de Nápoles a la monarquía hispánica. A partir de este momento, Gonzalo Fernández de Córdoba ejerce como primer virrey de Nápoles hasta 1507, año en el que el rey Fernando lo releva de su cargo y nombra a Juan de Aragón, conde de Ribagorza, movido por la sospecha y el temor de que el Gran Capitán se apoderara de dicho reino (Tambella 2014: 84). Según este pasaje, tanto el rey don Fernando como Fernández de Córdoba llegan a España desde Italia en el año 1508; pero lo cierto es que el monarca retornó a España en el verano de 1507 y el Gran Capitán lo hace en septiembre de ese mismo año. 
Leydas estas coplas platicaron en los blasones de lo otro. el gran capitan no hablo palabra sino mirar lo que el condestable y graçia dey deçian el condestable doblo el papel y dijo toma graçia dey que por cierto vos sois una gran lumbrera de nobles vos mereçeis que todos los grandes os agan cortesia [...] y el gran capitan le dijo graçia dey una persona tan honrrada como vos y que tanto honrrais a los buenos por que andais tan malbestido el respondio como quiere vs que ande. como yoos bestire mañana venid aqui a la ora que oy aveis benido y yo os are poner en el avito que mereçeis graçia dey le beso las manos por ello y bolvio otro dia al comer del gran capitan. el gran capitan le dijo en ora buena bengais graçia dey e dijo luego llamen mi camarero e mayordomo e benidos dixo tomad vosotros ambos a fulano y a çitano pajes y todos quatro tomar a graçia dey y agan lo que tengo mandado [...] en la camara dijo el camarero señor graçia dey mi señor el gran capitan manda que salgais vestido deestos bestidos que estan en este aparador desde la camissa asta los guantes y daos los en mil reales por su vida que cuestan mas con cosas de oro que van en ellos para con que honrreis buestra persona pues tanto honrrais a los buenos y enestos guantes van otros mil reales en pieças de oro para que envieis a vuestra muger que ha sabido que tiene neçesidad en salamanca y en este papel hos açe md. de otros mil reales de juro cada año en la renta de la seda de granada para que se os page dia a dia por toda buestra vida y rogad a dios por sus dias que mas os dara cada dia. (ff. $55^{\mathrm{r}}-57^{\mathrm{r}}$ ).

De este pasaje se infiere, asimismo, que Gracia Dei habría estado casado, pues en él se refiere a su esposa, ${ }^{34}$ que vivía en Salamanca y que pasaba ciertas necesidades económicas. Esta situación coincide, además, con datos que el autor indica en unos versos de la Criança y virtuosa dotrina, cuando solicita mecenazgo a un duque, marqués o conde:
Oyendo dezir vuestra señoría ser de tan alta magnificencia, le presupuse hazer reverencia según deseava días avía; y ansí, vine con tal osadía para que pueda servirle mejor, me haga merced con algo, Señor, que stoy puesto en gran agonía (h. $5^{v}$ ).

Por otro lado, la alusión a Salamanca probaría la vinculación de Gracia Dei con la misma, no solo en calidad de estudiante -"hijo del dicho studio"-, como nos anuncian los incunables de la Criança y del Blasón, sino que, además, debió de tener allí su residencia habitual y su familia hasta que comenzó al servicio de los Reyes Católicos, para después vincularse a la figura del Gonzalo Fernández de Córdoba, como se deriva de esta copla que nuestro autor le recita al monarca cuando éste le pregunta "cómo le va con el Gran Capitán":

$34 \quad$ Valverde Ogallar da a conocer en su tesis doctoral (2002: 274) el manuscrito 10343 de la BNE, que transmite una versión de este pasaje, con algunas variaciones y omisiones. Así, por ejemplo, la versión de este códice no recoge la referencia a la esposa de Gracia Dei ni las supuestas necesidades económicas, datos que, desde el punto de vista biográfico, son muy importantes. 
Muy alto rey de los godos
el gran capitán nonbrado
se llama paga por todos
porq con sotiles modos
tres mil reales me ha dado
mil de juro y mas los dos
para q escriva por vos
los trumphos y las açañas
q ha echo en vuestras Españas
a el me voy queda con dios (f. $58^{\text {r }}$ ).

De ser así, Pedro de Gracia Dei habría abandonado la corte del rey Fernando y habría pasado al servicio del Gran Capitán en torno al año 1508, cargo que debió de desempeñar, probablemente, hasta la muerte de su nuevo señor, el 2 de diciembre de 1515. La desvinculación de la corte de los Reyes Católicos debió de estar motivada, quizá, por alguna cuestión de índole económica, como parece subyacer de estas líneas, aunque también cabe la posibilidad de que Gracia Dei incurriese en comportamientos desleales, hipótesis que cobraría fuerza si atendemos a una pulla atribuida a Fadrique Enríquez de Cabrera, almirante de Castilla: "No es mi graçia gracia dey / pues que no contenta al Rey" (ID 7308). En cualquier caso, el conjunto de todos estos datos nos llevaría a afirmar que la relación entre Gracia Dei y Fernando el Católico no llegó a buen puerto.

Las lagunas a las que nos enfrentamos al intentar reconstruir la vida y trayectoria de Pedro de Gracia Dei también están presentes a la hora de establecer una fecha y lugar concreto de su muerte. En la Historia genealógica de la casa de los Osorio, una obra de Fernando Álvarez de Osorio, conservada en el ms. 3449 de la BNE, se da noticia de la muerte de Pedro de Gracia Dei, al indicar que era:

uno de los notables hombres que en nuestros siglos concurrieron destas antigüedades [heráldicas y genealógicas], el cual espiró en mis manos en esta villa de Zafra, á quien el conde (de Feria) mi señor, maguer niño á la sazón, le mandó hacer toda la honra que á tal varón pertenecía ${ }^{35}$.

Concluye Gayangos, a partir de un conjunto de datos de esta obra, que Pedro de Gracia Dei debió de morir en Zafra en 1530, mientras estaba al servicio del conde de Feria, aunque, realmente, esta fecha sería el terminus ante quem para su fallecimiento. De hecho, y en este sentido, encontramos de nuevo, en el Rosal de Nobleza de Antonio de Barahona, que Gracia Dei fue "Ynterprete de España, Criado del Gran Capitan y muerto en su serbicio" (BNE, ms. 6175, f. 82v), lo que, de ser cierto, Gracia Dei habría fallecido antes de 1515, ya que Gonzalo Fernández de Córdoba murió en diciembre de ese mismo año.

A la luz de lo expuesto, se evidencia, por tanto, la escasez de datos biográficos sobre Pedro de Gracia Dei. No obstante, las noticias que hemos recopilado, extraídas de sus

35 Cito a partir de la transcripción de Gayangos en el prólogo al Blasón de Gracia Dei (1882: VIII). 
propias obras y de otros documentos, nos permiten arrojar luz sobre este personaje que estuvo vinculado al entorno de los Reyes Católicos, en calidad de cronista y heraldo u oficial de armas. Después, pasaría al servicio de Gonzalo Fernández de Córdoba y terminaría los últimos años de su vida en la órbita del condado de Feria. Así, ampliamos el conocimiento sobre Pedro de Gracia Dei, ofreciendo nuevos datos que ponen de manifiesto la importancia de este autor a finales del siglo XV y principios del XVI en entornos tan ilustres. El prestigio del que pudo gozar Gracia Dei en vida se desprende también de algunos manuscritos y de las rúbricas que transmiten sus obras, pues suelen referirse a él como "notable hombre" y "sabio varón". Sin embargo, también queda patente que su vida estuvo marcada por continuas necesidades económicas que, sin lugar a dudas, intentó cubrir con su pluma y servicio a grandes señores. En cualquier caso, la investigación continúa abierta, y esperamos con futuras aportaciones contribuir a un mayor conocimiento de este autor, muy olvidado tanto por la historia como por la filología.

\section{BIBLIOGRAFÍA}

ALCOCER Y MARTÍNEZ, Mariano (1918-1931): Anales Universitarios: Historia de la Universidad de Valladolid. Valladolid: Imp. Castellana.

ANDRÉS, Gregorio de (1993): "Relación de la vida del Rey D. Pedro y su descendencia que es el linaje de los Castilla por Pedro Gracia Dei: Introducción y edición (I)". Cuadernos para investigación de la literatura hispánica. Vol. 18: 233-252.

ANDRÉS, Gregorio de (1994): "Relación de la vida del Rey D. Pedro y su descendencia que es el linaje de los Castilla por Pedro Gracia Dei: Texto. (Continuación) (II)". Cuadernos para investigación de la literatura hispánica. Vol. 19: 207-249.

ANTONIO, Nicolás (1788), Bibliotheca Hispana nova, Vol. II. Madrid: Biblioteca Nacional.

ANTONIO RUBIO, María Gloria de (2009): "Judíos, conversos e inquisición en Galicia (siglos XI-XVII)". Cuadernos de estudios gallegos. Tomo, LVI. Vol. 122: 171-189.

ASENJO GONZÁLEZ, María (1999): Espacio y sociedad en la Soria medieval (siglos $X I I I-X V)$. Soria: Diputación Provincial.

(2012-2014): "La exclusión como castigo. La pena de destierro en las ciudades castellanas del siglo xv". Anales de la Universidad de Alicante: Historia medieval. Vol. 18: 69-93.

BELTRÁN DE HEREDIA, Vicente (1966): Bulario de la Universidad de Salamanca (1219-1549). Salamanca: Secretariado de Publicaciones de la Universidad de Salamanca.

(1970): Cartulario de la Universidad de Salamanca (1218-1600), Vol. II. Salamanca: Ediciones de la Universidad de Salamanca.

Bibliografía Española de Textos Antiguos, Charles Faulhaber (coord.). Universidad de California: Berkeley. [http://bancroft.berkeley.edu/philobiblon/; 20/04/2020]. 
CABEZA DE LEÓN, Salvador; FERNÁNDEZ VILLAMIL, Enrique (1945): Historia de la Universidad de Santiago de Compostela. Santiago de Compostela: Universidad de Santiago de Compostela.

CARRASCO MANCHADO, Ana Isabel (2002): "La metáfora animal en la propaganda política de los Reyes Católicos (1474-1482)". Cahiers de linguistique et civilisation hispaniques médiévales. Vol. 25: 399-420.

CEBALLOS-ESCALERA Y GILA, Alfonso de (1993): Heraldos y Reyes de Armas en la corte de España. Madrid: Prensa y Ediciones Iberoamericanas.

COUCEIRO, Antonio (1951): Diccionario bio-bibliográfico de escritores gallegos, Vol. II. Santiago de Compostela: Sociedad de Bibliófilos Gallegos.

Cuentas de Gonzalo de Baeza: tesorero de Isabel la Católica, vol. II. (1995-1996): Ed. TORRE, Antonio de la; E. A. DE LA TORRE. Madrid: Patronato Marcelino Menéndez Pelayo.

DUTTON, Brian (1990-1991): El Cancionero del siglo XV (c. 1360-1520), vol. I. Salamanca: Universidad de Salamanca.

FERNÁNDEZ DE CÓRDOVA MIRALLES, Álvaro (2005): Alejandro VI y los Reyes Católicos. Relaciones político-eclesíasticas (1492-1503). Roma: Edizioni Università della Santa Croce.

FERNÁNDEZ DE OVIEDO, Gonzalo (1983): Batallas y quinquagenas, ed. Juan Pérez de Tudela y Bueso. Madrid: Real Academia de la Historia.

(2006): Libro de la cámara real del príncipe don Juan, oficios de su casa y servicio ordinario. Ed. Santiago Fabregat Barrios. Valencia: Publicacions de la Universitat de València.

GALLARDO, Bartolomé José (1888): Ensayo de una biblioteca española de libros raros y curiosos, vol. 3. Madrid: Gredos.

GARCÍA Y GARCÍA, Antonio (1989): "Los difíciles inicios (siglos XIII-XIV)”, Manuel Fernández Álvarez, Laureano Robles Carcedo y Luis Enrique Rodríguez-San Pedro Bezares (ed.), La Universidad de Salamanca. Salamanca: Ediciones Universidad de Salamanca, vol. 1: 14-34.

GIL PECES, Felipe (1998): "Universidad de Sigüenza". Memoria ecclesiae. Vol. 12: 185-188.

GÓMEZ MORENO, Ángel (2008): "Las universidades en la época de los Reyes Católicos", Nicasio Salvador Miguel y Cristina Moya García (eds.), La literatura en la época de los Reyes Católicos. Navarra: Iberoamericana, Vervuert, 59-77.

GÓMEZ REDONDO, Fernando (2012): Historia de la prosa de los Reyes Católicos: el umbral del Renacimiento, vol. I. Madrid: Cátedra.

GONZÁLEZ ARCE, José Damián (2016): La casa y corte del príncipe don Juan (14781497). Economía y etiquetas en el palacio del hijo de los Reyes Católicos. Sevi1la: Sociedad Española de Estudios Medievales.

GONZÁLEZ DE FAUVE, María Estela; LAS HERAS, Isabel; FORTEZA, Patricia (2006): "Apología y censura: posibles autores de las crónicas favorables a Pedro I de Castilla". Anuario de Estudios Medievales. Vol. 36/1: 111-144. 
GRACIA DEI, Pedro de, Criança y virtuosa dotrina, [s. i.t. , ca. 1488, Salamanca: Juan de Porras y Juan de Montejo].

Blasón general de todas las insignias del universo, [Coria, Bartolomé de Lila, 1489].

(1882), Blasón General y Nobleza del Universo. Prólogo de Pascual de Gayangos. Madrid: Imprenta M. Murillo.

GUILLÉN BERRENDERO, J. A. (2013): "Un oficio de la memoria honrada de la Monarquía: los reyes de armas y la idea de nobleza en Castilla en el siglo XII". Armas e Troféus. Revista de História, Heráldica, Genealogía e arte. Vol. 9: 481-503.

(2015): "Conocimiento, prestigio y blasones: reyes de armas e informantes de las Órdenes Militares ante el problema del honor y la común opinión en la Castilla del Seiscientos". Magallanica: revista de historia moderna. Vol. 2: 30-60.

HERNÁNDEZ GASSÓ, Héctor (2007): "El funcionariado letrado y su dimensión literario en la corte de los Reyes Católicos: el caso de Alonso Ramírez de Villaescusa", Armando López Castro y María Luzdivina Cuesta Torre (coords.), Actas del IX Congreso Internacional de la Asociación Hispánica de Literatura Medieval. León: Universidad de León, Servicio de Publicaciones, Vol. 2: 685697.

HERNÁNDEZ GASSÓ, Héctor (2009): “Los Reyes Católicos y la Universidad de Salamanca: formación al servicio del ideal monárquico", Jesús Cañas Murillo, Francisco Javier Grande Quejigo y José Roso Díaz (coord.), Medievalismo en Extremadura: estudios sobre literatura y cultura hispánicas de la Edad Media. Badajoz: Universidad de Extremadura, Servicio de Publicaciones, 119-132.

HERNÁNDEZ MARTÍNEZ, Pedro (2013): "La memoria de la historia oficial: Crónicas y cronistas en la España de los Reyes Católicos". Estudios sobre Patrimonio, Cultura y Ciencias Medievales. Vol. 15: 235-268.

INFANTES, Víctor (1995): "La Cortesía en verso de Pedro de Gracia Dei y su tratado La Criança y virtuosa doctrina (1488)", Rose Duroux (ed.), Traités de savoirvivre en Espagne et au Portugal du Moyen Âge à nos jours. Clermont Ferrand: Association des Publications de la Faculté des Lettres et Sciences Humanines de Clermont Ferrand, 43-54.

JARDIN, Jean-Pierre (2016) : "Pedro de Gracia Dei, roi d'armes et poète. Entre histoire, littérature et arts graphiques". e-Spania, Vol. 23. [https://journals.openedition.org/e-spania/25239?lang=es; 15/04/2020].

LADERO QUESADA, Miguel Ángel (1995): "El preste Juan de las Indias y los Reyes de armas castellanos del siglo xvı", Medievo hispano. Estudios in memoriam del prof. Derek W. Loman. Madrid: Sociedad de Estudios Medievales, 221234.

(1998): “La Casa Real en la Baja Edad Media". Historia. Instituciones. Documentos. Vol. 25: 327-350. 
MANGAS NAVARRO, Natalia A. (2020a): "Nuevas fuentes para la poesía de Pedro de Gracia Dei”. Revista de Cancioneros impresos y manuscritos. Vol. 9: 44-75. (2020b): "Un incunable poético de Pedro de Gracia Dei (89*GD): materialidad y contextos de un impreso con ejemplar mútilo". Revista de Poética Medieval. Vol. 34: 181-204.

MARCOS RODRÍGUEZ, Florencio (1964): Extractos de los libros de claustros de la Universidad de Salamanca: siglo xv (1464-1481). Salamanca: Universidad de Salamanca.

MARTÍN ABAD, Julián (2010): Catálogo Bibliográfico de Incunables de la Biblioteca Nacional de España, vol I. Madrid: Biblioteca Nacional.

MARTÍNEZ ALCORLO, Ruth (2015): "La Criança y virtuosa dotrina de Pedro de Gracia Dei, ¿un speculum principis para la infanta Isabel de Catilla, primogénita de los Reyes Católicos?", Marta Haro Cortés (ed.), Literatura y ficción: «estorias», aventuras y poesía en la Edad Media. Valencia: Publicacions de la Universitat de València, I, 375-390.

(2016), La literatura en torno a la primogénita de los Reyes Católicos: Isabel de Castilla y Aragón, princesa y reina de Portugal (1470-1498), Madrid: Universidad Complutense de Madrid [Tesis Doctoral].

PAREJO DELGADO, María Josefa (1998): "La obra de Antonio de Barahona y la historia social del reino de Jaén en la Baja Edad Media". Boletín del Instituto de Estudios Giennenses. Vol. 170: 129-183.

PAZ Y MELIÁ, Antonio (1892): Opúsculos literarios de los siglos XIV a XVI. Madrid: Sociedad de Bibliófilos Españoles.

PEREA RODRÍGUEZ, Óscar (2007): "Alta reina esclareçida: un cancionero ficticio para Isabel la Católica”, Luis Antonio Ribot García, Julio Valdeón Baruque y Elena Maza Zorrilla (coord.), Isabel la Católica y su época: actas del Congreso Internacional. Valladolid-Barcelona-Granada, 15 a 20 de noviembre de 2004. Valladolid: Instituto Universitario de Historia Simancas. Vol. 2: 1355-1383. (2017): "Pedro I y la propaganda antipetrista en la génesis y el éxito de la poesía cancioneril castellana, II". La corónica. Vol. 46/1: 151-181.

RÁBADE OBRADÓ, María del Pilar (1999): "La instrucción cristiana de los conversos en la Castilla del siglo xv". En la España Medieval. Vol. 22: 369-393.

RIQUER, Martín de (1986): Heráldica castellana en tiempo de los Reyes Católicos. Barcelona: Quaderns Crema.

RODRÍGUEZ-SAN PEDRO, Luis Enrique (2002): Bosquejo histórico de la Universidad de Salamanca. Salamanca: Ediciones Universidad de Salamanca.

RUIZ I CALONJA, Joan (1953-1954): "Fra Ambrosio Montesino, Fernando de Vedoya i Gràcia Dei, a la cort de Ferran el Catòlic". Estudis Romanics.Vol. Iv: 241-250.

RUMEU DE ARMAS, Antonio (1974): Itinerario de los Reyes Católicos (1474-1516). Madrid: CSIC, Instituto Jerónimo Zurita.

SANZ HERMIDA, Jacobo S (2004): “A vos Diana primera leona: literatura para la princesa y reina de Portugal, la infanta Isabel de Castilla". Península. Revista de Estudios Ibéricos. Vol. 1: 379-394. 
SUÁREZ FERNÁNDEZ, Luis (1992): La España de los Reyes Católicos (1474-1516). Madrid: Espasa Calpe.

(1998): Claves históricas en el reinado de Fernando e Isabel. Madrid: Real Academia de la Historia.

TAMBELLA, Franco Luciano (2014): "Redes de poder en el Sur de Italia en 1507. La sustitución de Gonzalo Fernández de Córdoba como virrey de Nápoles". Revista Chilena de Estudios Medievales: Vol. 6: 77-92.

VALDECASAS, Guillermo G. (1988): Fernando el Católico y el Gran Capitán. Granada: Comares.

VALVERDE OGALLAR, Pedro (2002): Manuscritos y heráldica en el tránsito a la modernidad: el libro de armería de Diego Hernández de Mendoza. Madrid: Universidad Complutense de Madrid.

VICENS VIVES, Jaime (2006): Historia crítica de la vida y reinado de Fernando II de Aragón. Zaragoza: Institución Fernando el Católico - CSIC.

\section{PERFIL ACADÉMICO Y PROFESIONAL}

Doctora en Literatura Española por la Universitat d'Alacant (2020).

Título de la tesis: La "Criança y virtuosa dotrina» de Pedro de Gracia Dei: estudio y edición crítica, bajo la dirección del Dr. Josep Lluís Martos y la Dra. Ana M ${ }^{\mathrm{a}}$ Rodado Ruiz.

Graduada en Filología Hispánica por la Universidad de Castilla-La Mancha (2016).

Máster en Investigación en Letras y Humanidades, por el mismo centro (2017).

Líneas de investigación: Literatura Medieval Española, filología material y estudio y edición crítica de textos.

Fecha de recepción: 30/04/2020

Fecha de aceptación: 08/06/2020 